cleo de Apoio à Pesquisa em Crítica Genética (NAPCG) e autor de $A$ tradição sempre nova [Ática, 1976], As figuras de linguagem [Ática, 1989] e Poética e poesia no Brasil (Colônia) [Imprensa Oficial SP, 2001], entre outros.

\section{MACHADO DE ASSIS, HISTORIADOR}

Sidney Chalhoub. [São Paulo: Companhia das Letras, 2003, 350 P.]

A crítica de um Machado de Assis absenteísta, indiferente às grandes questões sociais e políticas de que foi contemporâneo, entre elas, a Abolição e a República, correu paralela ao descaso com que era vista, até pouco tempo, a produção cronística do escritor. A raiz da acusação de alheamento a pesar sobre Machado é de longa data, podendo ter relação com o contexto brasileiro da segunda metade do século Xix. A ciência e aqueles que a praticavam, os "homens de ciência" da chamada geração de 1870 , ganham prestígio considerável, na medida em que se vêem como os melhor capacitados para falar a respeito do Brasil, contribuindo para o país sair do atraso e ingressar no rol das nações civilizadas.

"Homem de ciência, é só de ciência, nada o consterna fora da ciência" (1882), vai dizer Machado de Assis por meio de Simão Bacamarte, médico alienista que pôs a cidade inteira de Itaguaí num hospício. Se não bastasse a pecha de nefelibatas com que eram vistos os "homens de letras", Machado de Assis ainda publica, em 1881, Memórias póstumas de Brás Cubas, romance que, por se desviar do cânone realista-naturalista então vigente nas letras nacionais, irá desconcertar críticos literários até os mais abalizados, como Capistrano de Abreu, a emitir questionamento que ficou famoso: "Memórias póstumas são um romance?"
Representativa desse contexto de valorização da ciência é a célebre polêmica entre Sílvio Romero e Machado de Assis, cujo ponto de partida foi o ensaio deste último sobre a "nova geração", publicado em 1879 . No levantamento de autores surgidos na época, Machado criticava sobretudo o projeto de crítica literária e o didatismo da poesia de inspiração científica do escritor sergipano. A réplica de Silvio Romero foi o ensaio $\mathrm{Ma}$ chado de Assis, estudo comparativo de literatura brasileira (1897), em que comparadas, a partir de critério evolucionista e etnográfico, as obras de Tobias Barreto e Machado, a daquele era vista como superior à deste. Para além das disputas pessoais, a polêmica deixa transparecer o embate entre "homens de ciência", que se auto-identificavam a partir de postura intervencionista e atuante, e "homens de letras", que, na visão de autores como Romero, encontravam-se afastados das questões prementes de seu tempo.

Pode-se dizer que a crítica de um Machado absenteísta deixa de se sustentar quando a autoridade dos "homens de ciência" começou a ser questionada, e quando certas áreas da produção machadiana, no exemplo mencionado das crônicas, foram vistas não como obra menor, opinião de que participava o próprio Machado, que preferiu deixar ficar nos jornais em que foram publicadas as crônicas que escreveu, a fazer uma antologia com aquelas de sua preferência, na solicitação de Mário de Alencar. Decisivos para a mudança de imagem do escritor foram, entre outros, os livros de Brito Broca, Machado de Assis e a política e outros estudos (1957), Astrojildo Pereira, Machado de Assis (1959), e também, mais recentemente, a entrada em cena de brasilianistas, como John Gledson, autor de trabalhos exemplares, Machado de Assis, ficção e história (1986), reeditado em 
2003, e Machado de Assis, impostura e realismo (1991), e de críticos procedentes das ciências sociais e da história, responsáveis alguns deles por estudos clássicos, como os de Roberto Schwarz, Ao vencedor as batatas (1977), e Um mestre na periferia do capitalismo (1990), e agora este de Sidney Chalhoub, Machado de Assis, historiador, obra cujo título provocativo indicia inversão no estudo da obra machadiana.

A menção aos trabalhos de Gledson e Schwarz define a tradição crítica dentro da qual se insere a pesquisa de Chalhoub que, com o primeiro, participa da opinião de que Machado "comentou intensamente as transformações sociais e políticas de seu tempo" (p.18), para isso servindo-se da decifração e dissimulação. Como o segundo, pensa também que o romancista "expressa $e$ analisa aspectos essenciais do funcionamento e reprodução das estruturas de autoridade e exploração vigentes no período" (p.17). O interlocutor mais direto do historiador, Roberto Schwarz, é de quem resgata o conceito de paternalismo, por meio do qual empreende fina análise de Helena, romance escrito em 1876, mas que evoca o clima vigente na década de 1850 , entre as duas historicidades ocorrendo os debates políticos que vão culminar com a lei de 28 de setembro de 1871 , depois conhecida como Lei do Ventre Livre.

Ao mesmo tempo que a história de Estácio e Helena é lida como expressão da hegemonia da classe senhorial-escravista, cuja crise o romancista vai vivenciar na década de 1870, Chalhoub identifica no romance de 1876 elementos que põem em xeque a definição convencional de paternalismo, como também a separação entre paternalismo e escravidão, conforme leitura de Schwarz. Pesquisas realizadas a respeito da escravidão por historiadores, como Thompson, Genovese e Rebecca Scott, mostraram que "a vigência de uma ideologia paternalista não significa a inexistência de solidariedades horizontais e, por conseguinte, de antagonismos sociais" (p. 47). Por isso, na visão de Chalhoub, a personagem Helena não apenas se curva às prerrogativas da classe senhorial-escravista, dentro da qual se situa como pessoa livre, embora dependente, mas usa de astúcia e dissimulação como forma de expressar sua autonomia.

Assim como Helena, uma plêiade de outras personagens machadianas, que se situam igualmente na esfera dos dominados, vai procurar cavar, em meio à apertada malha do poder senhorial, espaço para poder sobreviver na prática do "discurso político possível", que envolvia, segundo o historiador, "a capacidade de atingir objetivos importantes utilizando de forma criativa - e reforçando, ao menos aparentemente - os rituais associados à própria subordinação" (p. 64). Dentre os vários exemplos de personagens que se exercitam nesse tipo de discurso, está aquele em que Capitu lembra Bentinho de como José Dias conseguira convencer D. Glória a consentir que o filho fosse ao teatro pela primeira vez, com o argumento de que "o teatro era uma escola de costumes". Como observa Chalhoub, é possível que fosse o agregado quem tinha, de fato, desejo de ir ao teatro, mas para isso precisava arrumar um jeito de a boa viúva fazer aquilo que ele queria, pensando que era vontade dela.

Em sintonia com a crítica machadiana mais recente que vem pondo de lado a divisão da obra do bruxo do Cosme Velho em duas fases distintas e opostas, a romântica e a realista, o historiador propõe, em relação àquele que seria o livro-divisor de águas, leitura original e instigante: "Em Memórias póstumas de Brás Cubas, Machado de Assis reescreveu Helena", com o ar- 
gumento de que os anos que configuram a trajetória de Brás, entre 1849 e 1869 , correspondem ao "período de hegemonia praticamente inconteste do paternalismo, da política de dominação assentada na imagem da inviolabilidade da vontade senhorial" (p. 73). Nem por isso a narrativa deixa de registrar oposições e resistências que provêm de Dona Plácida, a agregada que, como José Dias, aprendera a perseguir objetivos próprios, encontrando na adorada Virgília uma mestra sem par no exercício da "política cotidiana dos dependentes".

Enquanto Memórias póstumas é a reescritura de Helena, Chalhoub sugere que o mesmo acontece com Dom Casmurro em relação a Iaiá Garcia, pois que o romance de 1900 irá abordar as transformações sociais em torno das quais fora construído o de 1878 . Apenas que, agora, os detentores das prerrogativas senhoriais, no caso, Bentinho, passam a desconfiar dos subordinados, descobrindo mentiras, traições e disfarces no comportamento dos que dependem de seus favores. A compreensão de que os romances e as personagens de Machado de Assis estão um dentro do outro, como a fruta dentro da casca, leva Chalhoub a fazer observações pertinentes, como esta:

[...] resta a Dom Casmurro construir Bentinho como um Estácio levado ao paroxismo. Para completar o quadro, Capitu é edição revista e ampliada das astúcias de Helena - ou, mais rigorosamente, de laiá Garcia, que é versão desabrochada de Helena. [p. 85]

Ao modular o discurso da narrativa pelo discurso político dos dependentes, eivado de sinuosidades e duplos sentidos, a exigir do leitor atenção e paciência, se não quiser passar por "estácio" (sujeito tolo), Machado irá preferir a sugestão à evidência, opção estético-literária que está no centro da polêmica com Eça de Queirós, por conta do lançamento de O primo Basílio no Brasil, em 1878. A interpretação de que o narrador dos romances machadianos está investido de historicidade permite a Sidney Chalhoub identificar no comportamento do "defunto autor" Brás Cubas repercussões dos acontecimentos políticos e sociais da década de 1870 (muito embora a personagem tenha morrido em 1869), anos de intensa mobilização abolicionista, e que vão pôr em risco o poder dos senhores de escravos. No propósito de manter privilégios até então usufruídos, Brás vai lançar mão de idéias cientificistas européias então em voga no Brasil, em particular o darwinismo social, largamente empregado na época para explicar a partir dos critérios de origem e reprodução as desigualdades sociais. $O$ que acontecerá quando o narrador de Memórias póstumas, ao rever seu passado, tenta justificar o motivo pelo qual Eugênia, a "flor da moita" coxa, estava por isso incapacitada para o matrimônio e a maternidade.

Não apenas a obra de Machado de Assis está fincada na História, apresentando indícios irrefutáveis do processo histórico dos anos de 1870 , relacionados à crise da classe senhorial-escravista, por conta da promulgação da Lei do Ventre Livre, de que dão mostra as pertinentes e instigantes análises de Chalhoub, mas o historiador defende também a tese de que o próprio Machado vivenciou essa experiência histórica, quando trabalhou como chefe da segunda seção da Diretoria da Agricultura do Ministério da Agricultura, de 1873 até o final de 1880, conforme vai expor na última parte do livro Machado de Assis, historiador.

Pode-se dizer que, aqui, neste "capítulo tradicional de História” (p.12), Chalhoub está no seu elemento, 
lidando com desenvoltura com grande massa de documentos sobre os debates relacionados à aprovação e aplicação da lei de 1871 . Comparada às três primeiras, esta parte do livro é de leitura mais pesada, muito embora o historiador saiba driblar o peso dos longos e maçantes relatórios ministeriais com a leveza da ironia, técnica que, empregada com habilidade, revela o leitor formado no trato com a ficção de Machado de Assis.

Assim como para alguns estudiosos da obra machadiana, o resultado do primeiro recenseamento geral, em 1872, que vai acusar a existência de uma população de $70 \%$ de analfabetos, pode ter influenciado a grande guinada que irá ocorrer com $\mathrm{Me}$ mórias póstumas de Brás Cubas, na leitura de Hélio de Seixas Guimarães, em Os leitores de Machado de Assis (2004), Chalhoub aventa hipótese semelhante, mas em relação à experiência de Machado enquanto funcionário da Diretoria da Agricultura, onde lidava cotidianamente com a execução do fundo de emancipação dos escravos, criado pela lei de 1871, e cuja aplicação encontrava forte resistência entre os conselheiros do Império. Por seu lado, os "homens de letras" Joaquim Manuel de Macedo e José de Alencar, colaboravam na manutenção desse clima de resistência com a criação de obras, respectivamente, As vítimas-algozes (1869), O tronco do ipê (1871) e Til (1872), cujo propósito, na leitura do historiador, era mostrar que os escravos representavam uma ameaça para os senhores, ou então que a lei de 28 de setembro de 1871 fora responsável pelo desaparecimento do "paraíso senhorial" (p. 194).

Nesse cenário em que retórica parlamentar e literária davam-se as mãos para impedir, senão protelar ao má- ximo, que os senhores de escravos perdessem os bens a que tinham direito - o "elemento servil" -, Chalhoub identifica nas sociedades criadas por escravos libertos e seus descendentes, com o objetivo de promover a compra de seus membros "sujeitos" (isto é, ainda não alforriados), as vozes da resistência, aquela "solidariedade horizontal", a conviver com o paternalismo dos senhores de escravos.

Se dentre os méritos inquestionáveis de Machado de Assis, historiador está a refutação cabal do alheamento do escritor em relação à realidade político-social de seu tempo, para tanto a fatura do texto machadiano sendo interpretada como recriação ficcional dos acontecimentos históricos da década de 1870 - a crise da classe senhorial-escravista advinda com a promulgação da Lei do Ventre Livre -, contribuição não menor do livro de Sidney Chalhoub foi mostrar quão férteis podem ser os estudos (não apenas em relação à obra de Machado de Assis) que investigam a inter-relação literatura e história.

Silvia Maria Azevedo é professora no Departamento de Literatura da Faculdade de Ciências e Letras da UNESP, campus de Assis. Autora de $O$ rei dos jagunços de Manuel Benício: entre a ficção e a história [EDUSP, 2003] e organizadora de Romances e novelas [Landy, 2002].

UM DEFUNTO ESTRAMBÓTICO: ANÁLISE E INTERPRETAÇÃO DAS MEMÓRIAS POSTUMAS DE BRÁS CUBAS.

Valentim Facioli. [São Paulo: Nankin Editorial, 2002, 168 P.]

Um defunto estrambótico saiu em uma época de franca renovação dos estudos sobre Machado de Assis. A pro- 